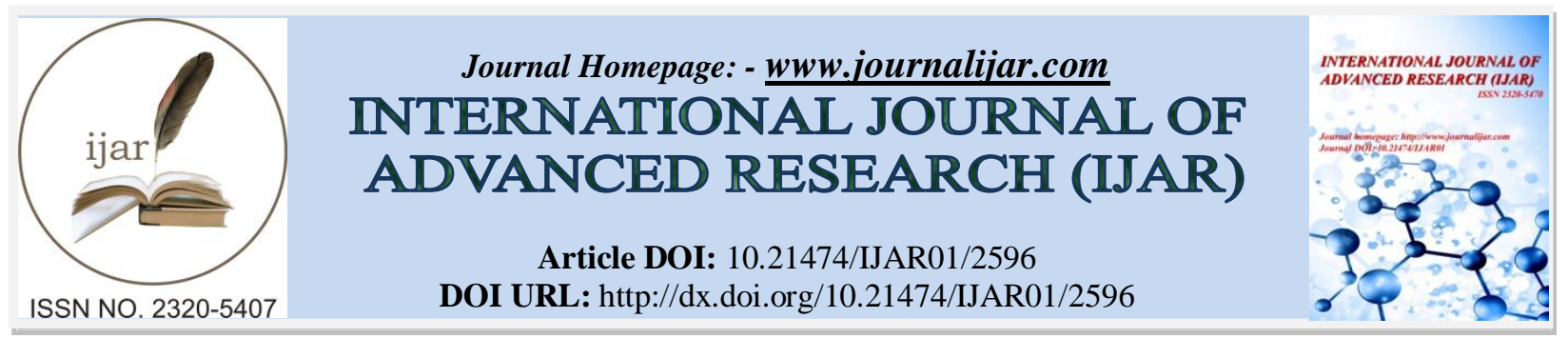

RESEARCH ARTICLE

\title{
EVALUATION OF CHEMISTRY TEACHERS' USE OF CONCEPT MAPPING STRATEGY IN SECONDARY SCHOOLS IN PLATEAU STATE - NIGERIA.
}

\section{Dr. Gongden, Ephraim Joel ${ }^{1}$, Prof. Oloyede Olufunmilayo $\mathbf{I}^{\mathbf{2}}$ and Mrs Ephraim, Esther $\mathbf{G}^{\mathbf{3}}$.}

1. Department of Science and Technology Education, University of Jos, P.M.B 2084, Jos, Plateau state - Nigeria.

2. Department of Science and Technology Education, Abubakar Tafawa Balewa University, P.M.B. 048 Bauchi, Bauchi State - Nigeria..

3. St. Piran's High School, P.O. Box 611, Jos, Plateau state - Nigeria.

\section{Manuscript Info}

\section{Manuscript History}

Received: 28 October 2016

Final Accepted: 27 November 2016

Published: December 2016

Key words:-

Concept mapping, concept maps,

instructional strategy, metacognitive

\section{Abstract}

The study was carried out with the objective of evaluating the acceptance of concept mapping as instructional strategy by secondary schools chemistry teachers in Plateau state - Nigeria. It sought to find out the frequency of its usage, the difficulty they experienced and the factors for such difficulties. The study was a survey research and utilized questionnaire for the collection of data. A sample of one hundred and twenty chemistry teachers was selected from the three senatorial zones using stratified random sampling and administered the questionnaire. The responses were analyzed using percentage. The study revealed that even though concept mapping metacognitive instructional strategy was effective in teaching chemistry, the strategy was not popular amongst the chemistry teachers; hence it was not in frequent use. The study also revealed that most chemistry teachers found it difficult to use concept mapping strategy. Some factors were found to be responsible for the negligence of the strategy among which are: ignorance of teachers about the strategy, lack of exposure to concept mapping strategy, difficulty to interpret relationship on concept maps and difficulty of constructing concept maps. The study recommended that efforts be made by the state ministry of education to organize seminars, workshops and conferences to enable chemistry teaches acquire the skills and competences needed for using concept mapping strategy. It also recommended among others that the curriculum content for prospective chemistry teachers in colleges and universities should include the development (or construction) of concept maps.

\section{Introduction:-}

One of the factors accountable for students' poor problem solving ability in chemistry has been the way the concepts are presented in the classroom (Gongden, 2015). Often times, they are not presented in a variety of contexts but verbal and formal thereby minimally effecting desired changes in students. It was in response to this that metacognitive strategies were suggested in order to shift emphasis from teacher- centred to student-centred learning. Metacognitive strategies are instructional strategies that help a learner to take charge of their learning through

Corresponding Author:- Dr. Gongden, Ephraim Joel.

Address:- Department of Science and Technology Education, University of Jos, P.M.B 2084, Jos, 
connecting new information to a former knowledge that they already possess. They are sequential processes that one uses to control cognitive activities and to ensure that a cognitive goal such as understanding a text or solving problem has been met (Waters \& Schneider, 2010). These processes help to regulate and oversee learning and consist of various processes as prioritizing, setting goals, self management, planning and monitoring cognitive activities, as well as checking the outcome of those activities. The strategies are not only student-centred but enable students construct and build their knowledge on the past experience thereby aiding conceptual understanding and problem solving. The use of these strategies has been associated with successful learning. McGuire (2008) suggested that metacognitive strategies should not only be used to improve teaching but that such strategies should be taught students. This will ensure the active participation of students in learning materials presented to them rather than remaining passive and taking down notes. Students will be involved throughout the class time in activities that help them construct their understanding of the material presented. Among the metacognitive strategies found useful in science education are the uses of analogies, concept maps and wait time. Others are science/technology/society discrepant events, real life situations, learning cycle approach, inquiry and mathematical problem solving (Gabel, 2003b).

Research has shown that a student's learning of a concept is greatly influenced by the previous concepts that they have acquired (Venville \& Treagust, 1997). Such researches are based on Ausubel's (1968) work who suggested that the most important single factor influencing learning is what the learner already knows. If students are taught to link their ideas, they might eliminate contradictions/misconceptions and create more robust conceptions. Conceptions can be quite discretely held by students. In Some cases, links are missing or incorrect, and students find it difficult to relate the science learned in the classroom to naturally occurring problem. The metacognitive strategies aim at correcting this. The ability of a student to successfully carry out problem-solving for example, depends on the way they organize their knowledge of science concepts. The way the information supplied to solve problems is organized also matters. To help a student solves problems, such information must be organized and symbolically represented (Gabel, 2003a). If this is done, then the student can define and apply them in solving the problem (Greeno \& Simon, 1984). The fundamental principle here is the capacity to integrate information. Better problem solvers are able to link salient information. Metacognitive instructional strategies become useful here as they enable the integrating and linkages between concepts for meaningful learning and problem solving (Greene and Simon, 1984).

Metacognitive strategies provide conceptual bridges between students' current knowledge level to new ideas (Muirhead, 2000). Ausubel's (1968) educational theory stresses the need for teachers to organize information in a manner that helps students grasp the principles and concepts. Students learn more when they are presented information in several modes (Gongden, 1998; Aksela, 2005). By increasing the amount of wait-time, for instance, teachers foster increased student discovers and more students-student interaction. Hence there is the need to employ metacognitive strategies in the science classes.

A concept map is an instructional strategy that involves graphical or diagrammatic representation of concepts achieved by selecting and arranging them into a meaningful hierarchy to show relationships between levels and among concepts (Olajenbesi \& Aluko, 2000). They are graphical tools for organizing, and representing knowledge. Usually, the concepts are enclosed in circles or boxes and the relationship between them indicated by a connecting line linking concepts which are connected with labeled arrows in a downward branching hierarchical structure. The technique for visualizing these relationships among different concepts is called concept mapping. Hence a concept map is a way of representing relations between ideas, images or words in the same way that a sentence diagram represents the grammar of a sentence, a road represents the location of highways and towns. Concept maps are visual or spartial representations of ideas and concepts interrelationships (Rye, 2001). Usually, a concept map begins with two or three concepts that are subsequently linked to other concepts. These are linked further to give a map of many concepts. As versatile tools in education, they serve to intentionally organize what a learner knows and engage him in relating new ideas to what he already knows (Jonassen, 1999). Chee and Wong (1996) described concept mapping as a process which involves the identification of key concepts in a domain of knowledge and the organization of these concepts into a hierarchical order.

Concept mapping was first developed by Novak (1979) as a cognitive tool for promoting meaningful learning. He believes that concept learning is important in science education and that concept mapping is a system of learning and instruction that is both consistent with the structure of scientific knowledge and the psychology of learning. Novak's work is based on Ausubel's cognitive theories which stressed the importance of prior knowledge in being 
able to learn new concepts. This strategy has received much attention from science education researchers and has been shown to be a useful tool to facilitate meaningful learning in science (Chee \& Wong, 1996). Concept maps have their origin in the learning movement called constructivism. Constructivists hold the view that learners actively construct knowledge. A variety of metacognitive strategies are based on this theory, concept mapping being amongst them. Constructivism is a theory of learning founded on the premise that, by reflecting on our experiences, we construct our own understanding of the world we live in (EBC, 2004). This theoretical framework holds that learning always builds upon knowledge that a student already knows; this prior knowledge is called a schema. Learners actively construct knowledge to make sense of the world, interpreting new information in terms of existing cognitive structures (Tobin \& Tippins, 1993). Every student has different experiences with their preexisting knowledge based on their experiences that is constructed in their mind (Taber, 2006). Children's minds are not a blank slate and knowledge cannot be imported without the child making sense of it according to their current conception. New information must pass through the filter of their prior knowledge and experience so they can construct a personal understanding based on reflecting on those experiences. By constructing a concept map, one reflects on what they know and what they don't.

Studies have revealed that the use of concept maps produce significantly higher positive attitude towards science as a school subject and caused a significantly better acquisition of science concepts (Uzuntiryaki \& Gedan, 2005). Concept maps help students focus on the relationships among concepts so that student's long term memories will accord with the scientific view (Gabel, 2003a). It particularly helps students understand concepts and relate them to one another thereby acquiring scientific conceptions, reduces students' anxiety toward learning, hence enhancing achievement and problem solving (Gongden, 2015; Uzuntiryaki \& Gedan, 2005). Furthermore, Concept maps provide an excellent tool for students to generate meaningful connections between chemical concepts and they provide information about students' conceptual understanding, (Francisco, Nakhleh, Nurrenbern \& Miller 2002; Cardellini, 2004). Concept maps have proved to be appropriate means of representing and organizing knowledge in a graphical way, and it helps students construct meaningful learning in an effective way (Aguirre - Perez, 2010). This happens because a learner pulls together information already known about a subject and understands new information as he learns. Students with the same concept mapping experience show a correlation between their concept mapping ability and their performance in achievement test as Chee and Wong (1996) noted. Osman (2008) noted that prospective teachers need to have the conceptual understanding necessary for using concept maps because when this is lacking, there will be difficulty.

\section{Statement of the Problem:-}

The effectiveness of concept mapping instructional strategy has been established by a number of studies such as Gongden (2015), Uzuntiryaki \& Gedan (2005) and Ezeugo and Agwagah (2000). It has been found to enhance meaningful learning in the sciences, facilitating sense-making and meaningful learning. It also improves students' problem - solving ability in some chemistry concepts. Despite the relevance of concept mapping to learning in chemistry and science in general, there is paucity of empirical study on the evaluation of the acceptance or otherwise of the strategy by chemistry teachers in Nigerian secondary schools. It is not clear whether the strategy is being employed by chemistry teachers in Nigerian secondary schools other than during experimental studies.

\section{Purpose of the Study:-}

The purpose of the study was to find out the extent to which concept mapping instructional strategy is being used by chemistry teachers in Nigerian secondary schools. Specifically, the study sought to find out:

1. The frequency with which teachers use the strategy to teach chemistry

2. Any difficulties that chemistry teachers encounter with the use of the strategy

3. Any reasons for such difficulties (or failure) in the use of the strategy

\section{Research Questions:-}

1. How often do chemistry teachers use concept mapping strategy to teach chemistry?

2. Do chemistry teachers experience any difficulties in using concept mapping instructional strategy?

3. What are some of the factors responsible for the difficulties teachers experience with concept mapping instructional strategy?

\section{Research Hypotheses:-}

1. Secondary schools chemistry teachers do not use concept mapping instructional strategies frequently to teach in their classrooms as they do with other strategies. 
2. Secondary schools chemistry teachers do not experience any difficulty when using concept mapping instructional strategies to teach in their classrooms.

3. There are no factors for the difficulties experienced by chemistry teachers in the use of concept mapping strategy

\section{Materials and Method:-}

The study was a survey research, one in which a group of people was studied by collecting and analyzing data from a sample considered to be representative of the entire group. The study utilized questionnaire for the collection of data. According to Oloyede and Ogunsola (2009), a survey research can be used to test the acceptability of certain educational innovations and in this case, the concept mapping strategy, hence its justification. Surveys are useful for determining the degree to which a desired objective is attained and to validate findings from experimental studies.

A sample of one hundred and twenty chemistry teachers was selected from senior secondary schools in the three senatorial zones of Plateau state using the stratified random sampling. Forty eight (48) teachers were drawn from the northern zone, forty two (42) from the central zone and thirty (30) from the southern zone. A ten - item questionnaire was developed by the researcher and the validity (face and content validity) established appropriately. It was also check for internal consistency (reliability) appropriately. The questionnaire sought to find out categories of information ranging from qualification of teachers, usage of concept mapping strategy, the effectiveness of the strategy, difficulties encountered ... to reasons for difficulty.

The researcher administered the questionnaire to the one hundred and twenty respondents with the help of three research assistants - one from each of the senatorial zones. There were one hundred and two males and eighteen females. The respondents were all chemistry teachers in the secondary schools. Where there were more than one chemistry teachers in a school, one was chosen through balloting. The respondents completed the questionnaire and returned the same. None of the one hundred and twenty got lost in the process of administration. The researcher used the responses for the analysis.

Percentage statistical tool was used for analyzing the categorical data in order to know how many and what percent of each value fell within each category. The result of the analysis was used to answer the research questions and test the hypotheses appropriately.

\section{Results:-}

The responses of the chemistry teachers (respondents) were pooled together and analyzed and interpreted accordingly.

Table 1:- General Statistics of the Respondents.

\begin{tabular}{|c|c|c|}
\hline Item & o of Respondents & $\%$ \\
\hline Total No of Respondents & 120 & $100.00 \%$ \\
\hline Qualifications: N.C.E only & 17 & $14.17 \%$ \\
\hline B.Sc.Ed & 34 & $28.33 \%$ \\
\hline B.Sc Chemistry + PGDE & 15 & $12.50 \%$ \\
\hline B.Sc Chemistry and other fields & 33 & $27.50 \%$ \\
\hline Higher National Diploma, H. N. D & 21 & $17.50 \%$ \\
\hline Teaching Experience: 1 - 3 yrs & 48 & $40.00 \%$ \\
\hline $4-6$ yrs & 39 & $32.50 \%$ \\
\hline $7 \mathrm{yrs}$ and above & 33 & $27.50 \%$ \\
\hline Ever heard of Concept Mapping Strategy? Yes & 63 & $52.50 \%$ \\
\hline No & 47 & $39.17 \%$ \\
\hline No Response & 10 & $08.33 \%$ \\
\hline How effective is concept mapping? Very effective & 13 & $10.83 \%$ \\
\hline Effective & 22 & $18.33 \%$ \\
\hline Unknown & 64 & $53.33 \%$ \\
\hline Not effective & 21 & $17.50 \%$ \\
\hline
\end{tabular}




\section{Research question one:-}

How often do chemistry teachers use concept mapping strategy to teach chemistry?

The response to the frequency of teachers' use of concept mapping strategy as represented by item "how often do you use concept mapping strategy in teaching chemistry students?" was as follows:

Table 2:- Frequency of Usage of Concept Mapping Strategy.

\begin{tabular}{|lcc|}
\hline Response & No of Respondents & \% of Respondents \\
\hline Very often & 08 & 06.70 \\
When the need arises & 10 & 08.30 \\
Rarely & 43 & 35.80 \\
Not at all & 59 & 49.20 \\
\hline
\end{tabular}

From the results, $6.7 \%$ of the teachers admitted to using the strategy frequently while $8.3 \%$ agreed that they use it only when the need arises. $35.8 \%$ admitted that they hardly use it while $49.2 \%$ said they do not use it at all.

Still another item asked respondents to say when they last used the concept mapping instructional strategy. The response to this was as follows:

Table 3:- The Last Time of Usage of Concept Mapping Strategy.

\begin{tabular}{|lcc|}
\hline When strategy was last used by teachers & No of Respondents & \% of Respondents \\
\hline One week ago & 04 & 03.33 \\
Two weeks ago & 06 & 05.00 \\
Three weeks ago & 07 & 05.83 \\
Four weeks ago & 20 & 16.67 \\
Five weeks and above & 23 & 19.17 \\
Never & 60 & 50.00 \\
\hline
\end{tabular}

Results in table 2 also show that the strategy is not in constant use amongst the teachers. Only a total of 37 (30.83\%) teachers said they've used it in the last one month of their teaching chemistry.

\section{Hypothesis one:-}

which states that secondary schools chemistry teachers do not use concept mapping instructional strategies frequently to teach in their classrooms as they do with other strategies was not rejected. The results show that secondary schools chemistry teachers in Plateau state do not use concept mapping instructional strategies frequently to teach in their classrooms as they do with other strategies.

\section{Research question two:-}

Do chemistry teachers experience any difficulties in using concept mapping instructional strategy? One of the items on the questionnaire asked if the teachers consider concept mapping strategy as a difficult strategy.

Table 4:- Response to the Difficulty of the Strategy

\begin{tabular}{|llll|}
\hline S/No & Responses & No. of Respondents & $\%$ \\
\hline 1 & Very difficult & 84 & 70.00 \\
2 & Not quite difficult & 23 & 19.17 \\
3 & Not at all & 13 & 10.83 \\
\hline
\end{tabular}

$70 \%$ of the respondents affirmed that concept mapping strategy is difficult to use. $19.17 \%$ agreed that it is not quite difficult while $10.83 \%$ admitted that the strategy is not difficult to us at all.

Another item sought to know how proficient the chemistry teachers were in the use of concept mapping instructional strategy. Their responses were as follows:

Table 5:- Proficiency in the Use of Concept Mapping Strategy

\begin{tabular}{|lll|}
\hline Response & No of Respondents & $\%$ \\
\hline Very well & 15 & 12.25 \\
Not quite & 42 & 35.00 \\
Not at all & 63 & 52.50 \\
\hline
\end{tabular}


The result in table 5 shows that most of the teachers are not proficient in the use of the instructional strategy. This may point to the possibility of its being a difficult strategy.

\section{Hypothesis two:-}

Secondary schools chemistry teachers do not experience any difficulty when using concept mapping instructional strategies to teach in their classrooms. The results presented in tables 4 and 5 show that chemistry teachers experience difficulty using concept mapping strategy for instruction in chemistry. The null hypothesis was rejected in favor of the alternate hypothesis. Therefore secondary schools chemistry teachers experience difficulties when using concept mapping instructional strategies to teach chemistry in their classrooms.

\section{Research Question three:-}

What are some of the factors responsible for the difficulties teachers experience with concept mapping instructional strategy?

The researcher sought to find out if some reasons or factors are responsible for the difficulties experienced by teachers in using concept mapping strategy. In doing so, many responses were received which analyzed and generally considered fall into the following categories:

a. Ignorance about concept mapping strategy

b. Lack of exposure to concept mapping strategy

c. Difficulty to interpret relationship on concept maps

d. Inability (or difficulty) to construct the concept maps by teachers and students

e. Construction of concept mapping is a tedious task requiring critical thinking

f. Construction of concept maps and usage can be time consuming

g. The use of concept mapping strategy can sometimes be a boring exercise.

h. Lack access to already constructed concept maps

i. Lack of knowledge of related chemical concepts

j. Not all topics can be taught using concept mapping.

$\mathrm{k}$. The effects of concept maps task is highly dependent on the topic/concept.

\section{Hypothesis three:-}

There are no reasons for the difficulties experienced by chemistry teachers in the use of concept mapping strategy. The responses given above show that teachers have their reasons for the difficulty they experienced in using concept mapping instructional strategy. The null hypothesis is rejected and the alternate accepted. Therefore, there are reasons for the difficulties experienced by chemistry teachers in the use of concept mapping strategy.

\section{Summary of Findings:-}

The study which is an evaluation of the use of concept mapping strategy by chemistry teachers in Plateau state Nigeria, has the following as findings:

a. Concept mapping instructional strategy is not been used frequently by chemistry teachers. Respondents acknowledged its effectiveness but showed that it not a popular strategy in the class.

b. Most chemistry teachers found it difficult to use concept mapping as a strategy in the classroom for teaching chemistry.

c. Various reasons account for the difficulty experienced by teachers in using the concept mapping strategy.

\section{Discussion of Results:-}

One of the findings of the research is that concept mapping instructional strategy is not been used frequently by chemistry teachers. The study acknowledged the effectiveness of the strategy but found that it is not a popular method of instruction. There has been relatively little use of it in chemistry classrooms in Plateau state. This result agrees with that of Pernaa and Aksela (2008) who found out that only 18\% of teachers used concept mapping strategy in chemistry. It also agrees with that of Caldwell et al. (2006) who discovered that concept mapping was been put to little use in mathematics classes in the United States. The reason may not be far-fetched. $45 \%$ of the teachers were not trained as teachers but are holders of B.Sc and HND in different fields other than chemistry or science education. About $47 \%$ of the respondents said they have not heard about the strategy. The research revealed that $50 \%$ of the respondents have never used the strategy while only about $31 \%$ have used it in the last one month. In addition, the respondents noted that the use of concept mapping strategy can sometimes be a boring exercise, a 
conclusion earlier reached by Gabel (2003b). the construction of the maps can be very tedious and requires critical thinking.

Another finding of the research was that the chemistry teachers found it difficult to use concept mapping as a strategy in the classroom for teaching chemistry. This finding agrees with result of earlier studies by Daley (2004) and Ehlen (nd). Both noted that concept mapping strategy can be difficult for use as a teaching strategy despite its effectiveness. The difficulty experienced may account for the lack of proficiency in the use of the strategy by the chemistry teachers as revealed in the study.

The study also established several reasons for the difficulty of the concept mapping strategy. These factors include ignorance about the strategy, lack of exposure to the strategy, difficulty to construct concept maps and interpret relationships among concepts, etc. Earlier studies have found similar reasons for the difficulty of teachers in using concept mapping strategy. Ehlen (nd) observed that the relationship among concepts and terms may elude learners. Sometimes the relationship among concepts in the concept maps may become difficult to interpret. In some cases, the concept mapping ends as an intricate puzzle rather than a learning tool. In another study, Daley (2004) .found out that concept maps can be very complex and hence difficult especially to participants that are unfamiliar with the format to read. Osman (2008) noted that prospective teachers need to have the conceptual understanding necessary for using concept maps because when this is lacking, there will be difficulty. The lack of exposure and ignorance about the strategy by chemistry teachers as found in this study may be due to the fact that most of the people who are teaching chemistry did not train as teachers. As such they have no knowledge of the principles and practice of education not to talk about instructional strategies. Lack of attending workshops and conferences which would serve to expose such teachers to different or new instructional strategies can also contribute to the difficulty.

\section{Conclusion:-}

The study evaluated the use of concept mapping strategy by secondary schools chemistry teachers in Plateau state. It found out that even though concept mapping strategy is considered an effective strategy for teaching chemistry, the strategy is unpopular as it is being used only by very few teachers. The study also established the fact that teachers experience difficulty using the concept mapping strategy in chemistry classes. The difficulty may be due to the sometimes complex nature of the concept maps, inability to construct concept maps for use, lack of exposure, familiarity with, and knowledge of the concept mapping strategy. Most of the teachers are not proficient in the use of concept mapping strategy. Most others are not chemistry graduates and have not received any training in methodologies of teaching and other principles of education.

The study recommended that efforts be made by the zonal directorates of education or the Plateau state ministry of education to organize seminars, workshops and conferences to enable chemistry teaches acquire the skills and competences needed for using concept mapping strategy in view of its effectiveness. It also recommended that teachers who do not have any training in education should proceed for at least, one year post - graduate diploma course in education. This will not only expose them to educational principles and practices, but qualifies them as professional teachers. Teachers who are competent in the use of concept mapping strategy should use it more frequently in chemistry classes, while those who do not use it should be encouraged to learn from others and start. Finally, the study recommended that the curriculum content for prospective chemistry teachers in colleges and universities should include the development (or construction) of concept maps for teaching chemistry.

\section{References:-}

1. Aguirre-Perez, C. (2010). An application of concept maps in chemistry: Teaching and learning of chemical bonding using Cmaptools. Retrieved August 4, 2011 from http://109. cgpublisher.com/proposals/538/index_html

2. Aksela, M. (2005). Supporting meaningful chemistry learning and higher-order thinking through computerassisted Inquiry: A design research approach. Chemistry Education. Centre. Department of Chemistry, University of Helsinki Finland.

3. Ausubel, D. P. (1968). Educational psychology: A cognitive view. New York: Holt Rhinehart and Winston.

4. Caldwell, W. H., Al -Rubaee, F., Lipkin, L., Caldwell, D. F., \& Campese, M. (2006). Developing a concept mapping approach to mathematics achievement in middle schools. Proceedings of the Second International Conference on Concept Mapping, San Jose, Costa Rica, 2006. 
5. Cardellini, L. (2004). Conceiving of concept maps to foster meaningful learning: An interview with Joseph D. Novak. Journal of Chemical Education, 81(9), 1303-1307.

6. Chee, T. S., \& Wong, P. (1996). The effects of incorporating concept mapping into computer assisted instruction. Paper presented at the Singapore Polytechnic, November 27.

7. Daley, B. (2004). Using Concept Maps in Qualitative Research. Proceedings of the First International Conference on Concept Mapping, Pamplona - Spain.

8. Educational Broadcasting Corporation. (2004). Constructivism as paradigm for teaching and learning. Retrieved May 28, 2014 from http://www.thirteen.org/edonline/concept2 class/constructivism/

9. Ehlen, P. (nd). eHow contributor. The Disadvantages of Concept Mapping. Retrieved on November, 23, 2016 from http://www.ehow.com/list_6749212_disadvantages-concept-mapping.html

10. Ezeugo,N. C. and Agwagah, U.N.V. (2000). Effects of concept mapping on students' achievement in algebra: implications for secondary mathematics education in the $21^{\text {st }}$ century. Abacus, Journal of Mathematical Association of Nigeria, 25 (1), $1-12$

11. Francisco, J. S., Nakhleh, M. B., Nurrenbern, S. C., \& Miller, M. L. (2002). Assessing student understanding of general chemistry with concept mapping. Journal of Chemical Education, 79 (2), 248-250.

12. Gabel, D. (2003a). Problem solving in chemistry: Research matters to the science teacher.

13. Retrieved June, 122013 from www.narst.org/publications/research/problem.cfm

14. Gabel, D. (2003b). Enhancing the conceptual understanding of science. Educational Horizons, Winter Edition, $70-76$.

15. Gongden, E. J. (1998). Analysis of the senior secondary two chemistry syllabus to determine areas of difficulty. Unpublished masters thesis, University of Jos.

16. Gongden, E. J. (2015). Comparative effects of two metacognitive instructional strategies on Gender and Problem solving abilities in selected Chemistry concepts. Unpublished Ph.D Thesis, A.T.B.U Bauchi.

17. Greeno, J. G., \& Simon, H. A. (1984). Problem solving and reasoning. In R.C.Atkinson, R. Herrnstein, G. Lindsey and R. D. Luce (Eds), Steven's handbook of experimental psychology (revised ed). New Tork; Wiley.

18. Jonassen, D. H. (1999). Constructivist learning environment on the web: Engaging students in meaningful learning. Ed Tech 99 Educational Technology Conference and Exhibition 1999: Thinking schools, learning nation.

19. McGuire, S. (2008). The role of metacognition in teaching geosciences. Paper presented at a workshop at the Louisiana state University, November. Retrieved November 30, 2011 from serc.carleton.edu

20. Muirhead, B. (2000). Advanced organizers. Retrieved June 23, 2001 from Advancedorg.

21. /selfdirectedlearning//educ@mindspring.com//http//ifets.ieee.org/discussions/discuss

22. Novak, J. D. (1979). Applying psychology and philosophy to the improvement of laboratory teaching. The American Biology Teacher, 41 (8), 466-470

23. Olajengbesi, A., \& Aluko, K. O. (2000). Effects of concept mapping and problem solving instructional strategies on secondary school learning outcomes in chemistry. African Research Review, 2 (1), 162-176.

24. Oloyede, O. I. \& Ogunsola, F(2009). Educational Research Methods and Statistics. Kaduna: Euneeks \& Associates

25. Osman, N. K. (2008). A student-centred approach: Assessing the changes in prospective Science teachers' conceptual understanding by concept mapping in a general chemistry Laboratory Research in Science Education, 38(1), 91-110

26. Pernaa, J. \& Aksela, M. (2008). Concept maps as meaningful learning tools in a web-based chemistry material. Proceedings of the third International Conference on Concept Mapping, Tallinn, Estonia \& Helsinki, Finland.

27. Rye, A. J. (2001). Enhancing teachers' use of technology through professional development on electronic concept mapping. Journal of Science and Technology, 10 (3), 223-235

28. Taber, K. S. (2006). Beyond constructivism: The progressive research programme into learning science. Studies in Science Education, 42, 125-184

29. Tobin, K., \& Tippins, D. (1993). Constructivism as a referent for teaching and learning. The practice of constructivism in science education, 1, 3-22

30. Uzuntiryaki, E., \& Gedan, O. (2005). Effect of conceptual change approach accompanied with concept mapping on understanding of solution concepts. Instructional Science, 33 (4), 311-339

31. Venville, G. J., \& Treagust, D. F. (1997). Analogies in biology education: Contentious issue.

32. The American Biology Teacher, 59 (5), 282-287

33. Waters, H. S., \& Schneider, W. (2010). Metacognition, strategy use, and instruction. New York: Guildford Press. 